\title{
Correction to: Clinical effects and gut microbiota changes of using probiotics, prebiotics or synbiotics in inflammatory bowel disease: a systematic review and meta-analysis
}

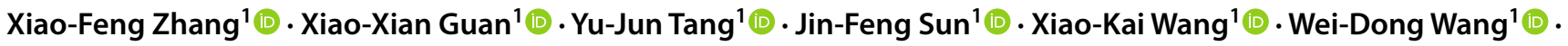 \\ Jian-Ming $\operatorname{Fan}^{1}$ (D)
}

Published online: 24 May 2021

(c) Springer-Verlag GmbH Germany, part of Springer Nature 2021

Correction to: European Journal of Nutrition

https://doi.org/10.1007/s00394-021-02503-5

Some of the studies included in this systematic review and meta-analysis assessed a probiotic formulation formerly known as VSL\#3. Since 2016, the probiotic formulation that was assessed in these studies should be referred to by the generic name 'De Simone Formulation'. The current product sold under the VSL\#3 brand is not the same formulation as the De Simone Formulation.

The original article can be found online at https://doi.org/10.1007/ s00394-021-02503-5.

Jian-Ming Fan

fan5746067@126.com

1 Department of Nutrition and Food Hygiene, College

of Public Health, Zhengzhou University, 100 Kexue Avenue,

Zhengzhou 450001, Henan, China 